\title{
SHOCK WAVE PROPERTIES OF ANORTHOSITE AND GABBRO
}

\author{
Mark B. Boslough ${ }^{1}$ and Thomas J. Ahrens
}

Seismological Laboratory, California Institute of Technology, Pasadena

\begin{abstract}
Shock wave experiments have been conducted on San Gabriel anorthosite and San Marcos gabbro to peak stresses between 5 and $11 \mathrm{GPa}$ using a $40-\mathrm{mm}$-bore propellant gun. Particle velocity wave profiles were measured directly at several points in each target by means of electromagnetic gauges, and Hugoniot states were calculated by determining shock transit times from the gauge records. The particle velocity profiles yielded sound velocities along the release adiabats which indicate a retention of shear strength upon shock compression for anorthosite, with a loss of strength upon release to nearly zero stress. Sound velocities of anorthosite shocked to peak stresses between 6 and $10 \mathrm{GPa}$ were measured to be between 5.1 and $5.3 \mathrm{~km} / \mathrm{s}$ upon release to nearly zero stress as compared to $\sim 6.9$ and $5.4 \mathrm{~km} / \mathrm{s}$ for the expected longitudinal and bulk wave speeds. Stress density release paths in the anorthosite indicate possible transformation of albite to jadeite + (quartz or coesite), with the amount of albite transformed ranging from as low as 0.05 to as much as 0.19 mass fraction in the 6-10 GPa shock stress range. Electrical interference effects precluded the determination of accurate release paths for San Marcos gabbro. Because of the apparent loss of shear strength during unloading from the shocked state, the fluidlike rheology of anorthosite which is indicated implies that calculations of energy partitioning due to impact onto planetary surfaces based on elasticplastic models will underestimate the amount of internal energy deposited in the impacted surface material.
\end{abstract}

\section{Introduction}

The plagioclase feldspar-bearing rocks, anorthosite and gabbro, are important components of the lunar and terrestrial crusts. It is necessary to understand the behavior of such rocks under high dynamic stress in order to model cratering processes which result from hypervelocity impacts and to characterize the stress history of rocks which have been subjected to shock loading on planetary surfaces (such as the moon) and meteorites. Shock wave studies of these and similar materials have been conducted in the past [Ahrens et al., 1969; McQueen et al., 1967; Jeanloz and Ahrens, 1980; Boslough et al., 1985a], but in these studies the data are limited to the Hugoniot state and in some cases a single state on the release isentrope. By employing particle velocity gauges, a complete stress-strain history subsequent to shock compression can be determined, along with sound velocity information [Fowles and Williams, 1970; Cowperthwaite and Williams, 1971; Seaman, 1974]. Particle velocity experiments supply detailed release paths, which provide better constraint for mechanical properties and polymorphism than is available with Hugoniot experiments alone.

Peterson et al. [1970] used particle velocity gauges to determine release paths of playa alluvium, tonalite, and novaculite shocked to stresses up to $5 \mathbf{G P a}$. They attri-

$\overline{1}$ Now at Sandia Laboratories, Albuquerque, New Mexico.

Copyright 1985 by the American Geophysical Union.

Paper number 4B5000.

0148-0227/85/004B-5000\$05.00 buted high rarefaction velocities and steep release paths in the stress-density plane to irreversible compaction. Grady et al. [1974] carried out experiments on polycrystalline quartz (novaculite) to $40 \mathrm{GPa}$, using a combination of particle velocity and manganin stress gauges to determine release adiabats. They concluded that a partial quartzstishovite transformation takes place above $15 \mathrm{GPa}$, with the quantity of material transformed an increasing function of peak stress, and that the Hugoniot states are not on the quartz-stishovite coexistence curve. Similar experiments were conducted on polycrystalline quartz and perthitic feldspar by Grady et al. [1975] and Grady and Murri [1976], who used manganin stress gauges to determine Hugoniot sound velocities and found that these rocks lose shear strength when shocked to pressures above $20 \mathrm{GPa}$. Larson and Anderson [1979] used particle velocity gauges to study limestone and tuff at lower stress levels (4 GPa) and attributed the observed time-dependent behavior to the closing of pores in these rocks.

In this paper we present new Hugoniot data on San Gabriel anorthosite and San Marcos gabbro to $11 \mathrm{GPa}$ Release paths in the stress-density plane and sound velocities are reported, as determined from particle velocity data.

\section{Experimental Methods}

The particle velocity experimental design is similar to those of Grady et al. [1974], Larson and Anderson [1979], and Kondo et al. [1980] and makes use of electromagnetic particle velocity gauges [Dremin and Shvedov, 1974]. Gauges are oriented in a steady, uniform magnetic field such that the active element of the gauge, the magnetic field lines, and the direction of motion are all mutually perpendicular and the gauge leads are parallel to the magnetic field. An electromotive force is induced along the length of the gauge element, proportional to the velocity of the gauge. For a gauge with effective length $\mathrm{L}$ in a magnetic field $B$, the potential measured across the gauge leads is

$$
\mathrm{V}(\mathrm{t})=\mathrm{BLu} \mathrm{u}_{\mathrm{p}}(\mathrm{t})
$$

where $u_{p}$ is the particle velocity of the material in which the gauge is embedded. These signals are recorded by an array of cathode ray oscilloscopes.

Gauges were photoetched from $10.0-\mu \mathrm{m}$-thick copper foil with a 12.5- $\mu$ m-thick polyamide (Kapton) film backing. The active elements of the gauges were $0.9-1.0 \mathrm{~cm}$ long. The precise effective gauge length (used in equation (1)) is dependent on the geometry of the gauge due to electromagnetic edge effects from the leads and the finite gauge width. It is about equal to the center-to-center lead distance of $0.95 \mathrm{~cm}$.

Rock samples were constructed by sawing rectangular slabs about $3.2 \mathrm{~cm}$ by $4.5 \mathrm{~cm}$ and grinding them to a uniform thickness of about $1.5 \mathrm{~mm}$. Archimedean densities were determined for each slab individually. Four slabs were bound together with epoxy, with three gauges at the interfaces and one at the free surface. The mean thickness of the glue at each interface was $\sim 9 \mu \mathrm{m}$. All four sets of gauge leads extended from the sample in the same direction along the long axis of the rock slabs. The gauge leads were connected to oscilloscopes via coaxial cables.

In Figure 1 the particle velocity experimental assembly is shown schematically, with a rock target mounted on the 


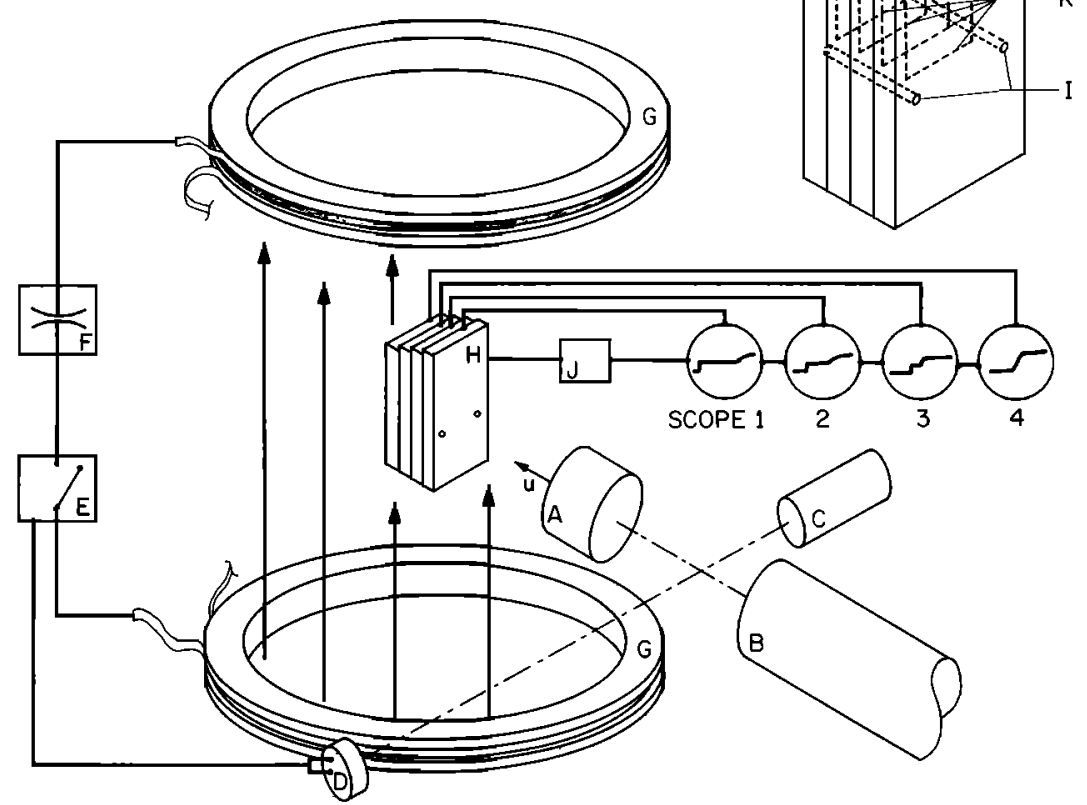

Figure 1. Schematic drawing of particle velocity experiment, with major components indicated: A, polycarbonate projectile; B, 40-mm bore gun barrel; C, timing laser; D, photodetector; E, high-power switch (ignitron); F, capacitor bank; G, Helmholtz coils; H, rock target; I, selfshorting trigger pins; J, fiducial pulse generator; $K$, copper foil particle velocity gauge elements.

center of the axis of a set of Helmholtz coils, which supply the magnetic field. To ensure mutual perpendicularity between the gauge, field, and particle velocity, the target is aligned with the gun barrel by using a laser beam.

The Helmholtz coils have a radius and separation of $14.1 \mathrm{~cm}$ and are wound with four turns of gauge 10 copper wire. The magnetic field at the center point of the coil axis is constant to third order and equal to

$$
\mathrm{B}=\frac{8 \mu_{\mathrm{o}} \mathrm{IN}}{(5)^{3 / 2} \mathrm{r}}
$$

where $\mu_{0}$ is the permeability constant, I is the current, $N$ is the number of turns, and $r$ is the radius and distance between coils. The field is typically about $1.8 \mathrm{kG}$. The current is supplied by a bank of five $15-\mu \mathrm{F}$ capacitors

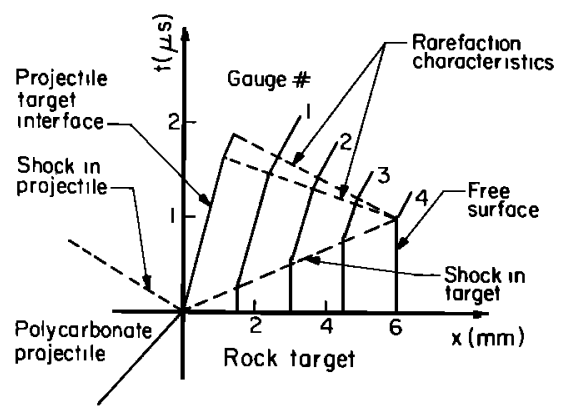

Figure 2. Particle velocity experiment represented by $x-t$ diagram. Projectile approaches stationary target from left and impacts at $t=0$. charged to $5.0 \mathrm{kV}$ and reaches its peak value of about 6.7 $\mathrm{kA}$ in about $60 \mu \mathrm{s}$. Because the time scale of the experiment, which is determined by the shock and rarefaction transit times through the sample $(\approx 2 \mu \mathrm{s})$, is short compared to the period of the capacitor-coil circuit $(\approx 250 \mu \mathrm{s})$, the timing can be controlled so that impact occurs at the peak current, when the field is effectively constant.

Targets were shock-loaded by impact of flat-faced polycarbonate (Lexan) projectiles fired from a $40-\mathrm{mm}$ bore propellant gun at velocities from 1.4 to $2.4 \mathrm{~km} / \mathrm{s}$. Projectile velocities were determined using the time intervals between the projectile obscuring a series of laser beams [Ahrens et al., 1971]. The geometry and time history of a typical experiment is illustrated by means of an $x$-t diagram in Figure 2. The stationary rock target lies to the right of the origin, with four particle velocity gauges initially at in tervals of $1.5 \mathrm{~mm}$. The polycarbonate projectile approaches

TABLE 1. San Gabriel Anorthosite Mineralogy

\begin{tabular}{lc}
\hline \multicolumn{1}{c}{ Mineral } & Volume $\%$ \\
\hline Plagioclase & 91 \\
White Mica & 6 \\
Epidote & 3 \\
Opaques & trace \\
Quartz & trace \\
Apatite & trace \\
\hline
\end{tabular}

Analysis by S. Rigden.

* $\mathbf{A n}_{40}$. 
from the left and strikes the $x=0$ surface of the target at time $t=0$, driving a shock wave to the right into the rock and to the left in to the projectile. Each gauge is stationary until overtaken from the left by the shock wave, at which time it begins moving with the particle velocity associated with the Hugoniot state. The shock wave reflects from the free surface as a rarefaction wave, and each gauge again accelerates to the right as this wave passes through it from the right.

San Gabriel anorthosite samples were collected in the San Gabriel Mountains near Pasadena, California. This rock type is highly variable in composition and texture and has been studied in detail by Carter [1982]. The particular specimen used in these experiments had randomly oriented plagioclase crystals with a mean grain size of $1-2 \mathrm{~mm}$. Significant alteration was observed at grain boundaries and the mineralogy, given in Table 1 , was determined with a petrographic microscope. The plagioclase was found to have a mean composition of $\mathrm{An}_{40}$ as determined from extinction angle measurements. An electron microprobe analysis indicated a composition of $\mathrm{An}_{38}$. The San Marcos gabbro was obtained near Escondido, California. This intrusion has been studied petrologically by Miller [1937].
TABLE 2. San Marcos Gabbro Mineralogy

\begin{tabular}{lc}
\hline Mineral & Volume \% \\
\hline Plagioclase & 67.9 \\
Amphibole & 22.5 \\
Clinopyroxene & 1.5 \\
Orthopyroxene & 1.1 \\
Quartz & 1.4 \\
Biotite & 0.9 \\
Opaques & 4.3 \\
Alakali feldspar & trace \\
Calcite & trace \\
Chlorite & trace \\
Apatite & trace \\
\hline
\end{tabular}

Analysis by $\mathbf{R}$. Hill.

Samples from the same specimen used in the present study were used in impact and in spall strength experiments by Lange et al. [1984]. The mineralogy is tabulated in Table 2.

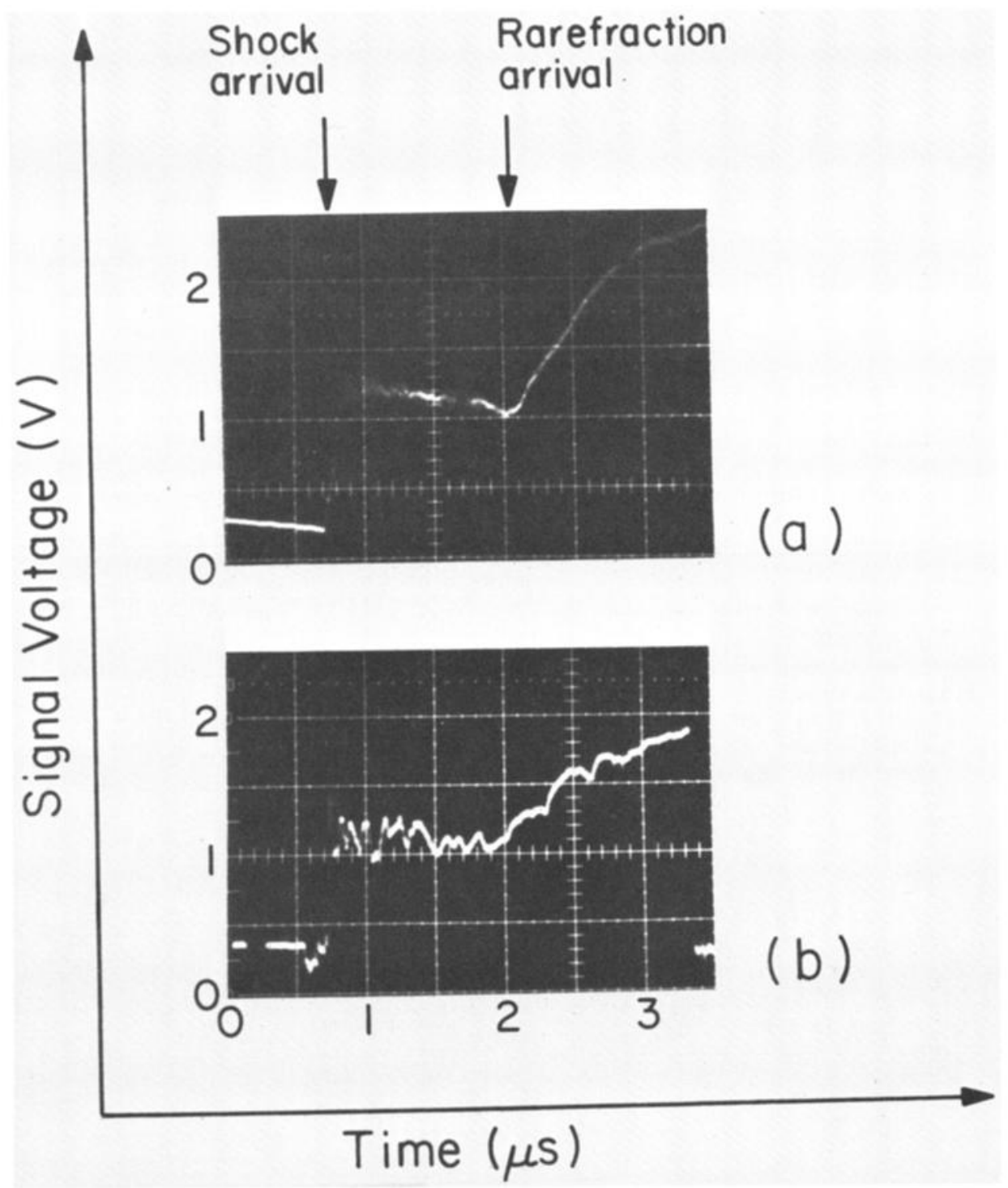

Figure 3. Oscillograms of particle velocity-time profiles in (a) anorthosite and (b) gabbro. Gabbro signals are significantly noisier, presumably due to presence of quartz grains. 


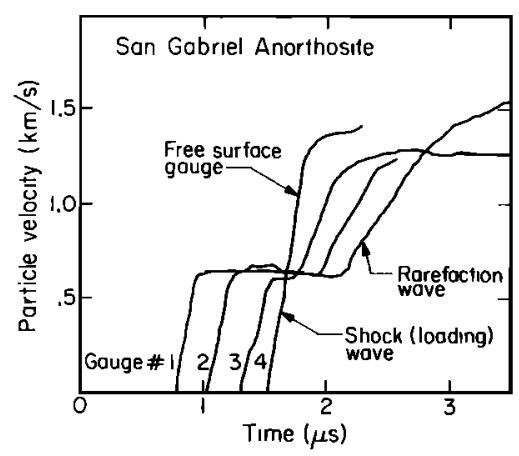

Figure 4. Digitized particle velocity gauge records from experiment $40-571$ in which anorthite was shocked to 10 $\mathrm{GPa}$.

Results

Typical particle velocity records for shocked anorthosite and gabbro are shown in Figure 3 . The sudden increase corresponds to shock wave arrival, and the second increase corresponds to the acceleration from free surface rarefaction. The gabbro records were lound to be significantly noisier than the anorthosite records in all cases. The deviations in particle velocity appear to be too large to be caused by differential grain motion. Instead, they are probably electrical effects which result from the presence of piezoelectric quartz grains in the gabbro, whereas the anorthosite was relatively free of quartz.

Digitized oscilloscope records for anorthosite shocked to $10 \mathrm{GPa}$ are shown in Figure 4. Synchronization of the four signals in time was achieved by means of a fiducial pulse received simultaneously at each oscilloscope. Shock transit times were taken from the interval between arrival at different gauges and were used to determine shock velocity. The known projectile velocity and polycarbonate Hugoniot [Marsh, 1980] were used with an impedance match solution [McQueen et al., 1970] to determine the Hugoniot states achieved in the rocks. In principal, the Hugoniot state could be determined by measuring the particle velocity of the shocked state directly. This would require a series of gauge calibration shots and a precise measurement of the pulsed magnetic field. By our method each shot was selfcalibrating: the particle velocity of the shock state was determined by impedance matching, from which we obtained a calibration factor to get the subsequent particle velocity history. Eulerian sound velocities were determined from the transit time of the free surface rarefaction front and the Hugoniot density. Hugoniot states and sound velocities for both rocks are given in Tables 3 and 4 .

It is evident from Figure 3 that the rise time of the shock records are as great as 200 ns. The rise time of a gauge itself is limited by its deviation from parallelism to the planar shock (tilt) and by the time it takes the gauge to reverberate up to the particle velocity of the surrounding medium. The thickness of the gauge-backing-glue layer is about $30 \mu \mathrm{m}$. Several shock transit times through this layer should accelerate it in less than $50 \mathrm{~ns}$. Other experiments carried out on the same gun demonstrate that shock tilts are no greater than $\sim 50 \mathrm{~ns}$ across a $1-\mathrm{cm}$ element [Watt and Ahrens, 1983]. The long observed rise time is therefore at least partially due to the shock wave itself. We believe that the grainy texture of the rocks used in these experiments causes a deviation from ideal shock planarity, spreading out its time of arrival over a finite area of the sample. This does not affect the results to first order, as differential methods are used in reducing the data.

The observed release waves are nonsteady simple waves and can be inverted to stress density release paths by numerically integrating the equations for conservation of mass and linear momentum [Cowperthwaite and Williams, 1971]:

$$
\begin{aligned}
& \left(\frac{\partial \rho}{\partial \mathrm{u}_{\mathrm{p}}}\right)_{\mathrm{h}}=\frac{\rho^{2}}{\rho_{\mathrm{o}} \mathrm{C}\left(\mathrm{u}_{\mathrm{p}}\right)} \\
& {\left[\frac{\partial \sigma}{\partial \mathrm{u}_{\mathrm{p}}}\right]_{\mathrm{h}}=\rho_{\mathrm{o}} \mathrm{C}\left(\mathrm{u}_{\mathrm{p}}\right)}
\end{aligned}
$$

where $\rho$ is the density, $\rho_{0}$ is the initial density, $\sigma$ is the stress, $u_{p}$ is the particle velocity, and $h$ is the Lagrangian space coordinate along the direction of wave propagation. The Lagrangian sound velocity is determined by the finite difference approximation

$$
\mathrm{C}\left(\mathrm{u}_{\mathrm{p}}\right) \approx \frac{\Delta \mathrm{h}}{\Delta \mathrm{t}}
$$

where $\Delta \mathrm{h}$ is the initial distance between gauges and $\Delta \mathrm{t}$ is the transit time for a disturbance with particle velocity $u_{p}$. In the case of anorthosite the release paths are smooth and single-valued (Figure 3a). The oscilloscope records were digitized and integrated directly. The resulting release paths are consistent and are plotted in Figure 5. Owing to the noisiness of the gabbro records (Figure $3 \mathrm{~b}$ ), it was necessary to approximate the rarefaction waves by smooth curves before integrating. Complete release paths were not obtained, and the partial release paths for San Marcos gabbro are less consistent than those for anorthosite (Figure 6). Eulerian sound speeds, equal to $\left(\rho_{\mathrm{o}} / \rho\right) \mathrm{C}\left(\mathrm{u}_{\mathrm{p}}\right)$, were also calculated for the release paths. These are plotted for anorthosite as a function of stress in Figure 7.

In practice, it was necessary to carry out some adjustment of the data before integrating. A small amount of baseline drift existed in the data due to the nonzero magnetic field flux through the gauge loop. This drift was slow

TABLE 3. San Gabriel Anorthosite Shock Wave Data

\begin{tabular}{lcccccrr}
\hline Shot & $\begin{array}{c}\text { Projectile } \\
\text { Velocity, } \\
\mathrm{km} / \mathrm{s}\end{array}$ & $\begin{array}{c}\text { Initial } \\
\text { Density, } \\
\mathrm{Mg} / \mathrm{m}^{3}\end{array}$ & $\begin{array}{c}\text { Shock } \\
\text { Velocity, } \\
\mathrm{km} / \mathrm{s}\end{array}$ & $\begin{array}{c}\text { Particle } \\
\text { Velocity, } \\
\mathrm{km} / \mathrm{s}\end{array}$ & $\begin{array}{c}\text { Pressure, } \\
\mathrm{GPa}\end{array}$ & $\begin{array}{c}\text { Density, } \\
\mathrm{Mg} / \mathrm{m}^{3}\end{array}$ & $\begin{array}{r}\text { Solocity, } \\
\mathrm{km} / \mathrm{s}\end{array}$ \\
\hline \multirow{4}{*}{$40-572$} & 1.575 & 2.656 & 5.648 & 0.394 & 5.91 & 2.855 & 6.90 \\
& \pm 0.050 & \pm 0.013 & \pm 0.055 & \pm 0.022 & \pm 0.31 & \pm 0.011 & \pm 0.36 \\
$40-570$ & 1.881 & 2.653 & 5.725 & 0.493 & 7.47 & 2.903 & 7.59 \\
& \pm 0.050 & \pm 0.007 & \pm 0.117 & \pm 0.020 & \pm 0.28 & \pm 0.014 & \pm 0.10 \\
$40-571$ & 2.351 & 2.653 & 5.985 & 0.644 & 10.23 & 2.973 & 8.39 \\
& \pm 0.050 & \pm 0.007 & \pm 0.032 & \pm 0.020 & \pm 0.30 & \pm 0.011 & \pm 0.44 \\
\hline
\end{tabular}


TABLE 4. San Marcos Gabbro Shock Wave Data

\begin{tabular}{lcrcrrrr}
\hline Shot & $\begin{array}{c}\text { Projectile } \\
\text { Velocity, } \\
\mathrm{km} / \mathrm{s}\end{array}$ & $\begin{array}{c}\text { Initial } \\
\text { Density, } \\
\mathrm{Mg} / \mathrm{m}^{3}\end{array}$ & $\begin{array}{c}\text { Shock } \\
\text { Velocity, } \\
\mathrm{km} / \mathrm{s}\end{array}$ & $\begin{array}{c}\text { Particle } \\
\text { Velocity, } \\
\mathrm{km} / \mathrm{s}\end{array}$ & $\begin{array}{c}\text { Pressure, } \\
\mathrm{GPa}\end{array}$ & $\begin{array}{c}\text { Density, } \\
\mathrm{Mg} / \mathrm{m}^{3}\end{array}$ & $\begin{array}{c}\text { Sound } \\
\text { Velocity, } \\
\mathrm{km} / \mathrm{s}\end{array}$ \\
\hline & & & & & & & \\
$40-569$ & 1.394 & 2.907 & 6.487 & 0.286 & 5.39 & 3.041 & 6.5 \\
& \pm 0.009 & \pm 0.008 & \pm 0.035 & \pm 0.011 & \pm 0.20 & \pm 0.004 & \pm .1 \\
$40-573$ & 1.968 & 2.886 & 6.11 & 0.474 & 8.36 & 3.129 & 8.5 \\
& \pm 0.006 & \pm 0.001 & \pm 0.30 & \pm 0.016 & \pm 0.14 & \pm 0.022 & \pm 0.4 \\
$40-555$ & 2.187 & 2.892 & 6.66 & 0.515 & 9.91 & 3.135 & -- \\
& \pm 0.050 & \pm 0.007 & \pm 0.19 & \pm 0.020 & \pm 0.34 & \pm 0.015 & - \\
$40-556$ & 2.242 & 2.929 & 6.898 & 0.515 & 10.41 & 3.165 & 7.0 \\
& \pm 0.032 & \pm 0.039 & \pm 0.042 & \pm 0.048 & \pm 0.84 & \pm 0.020 & \pm 0.5 \\
$40-574$ & 2.418 & 2.874 & 6.404 & 0.608 & 11.19 & 3.176 & 6.7 \\
& \pm 0.025 & \pm 0.049 & \pm 0.016 & \pm 0.052 & \pm 0.77 & \pm 0.026 & \pm 0.5 \\
\hline
\end{tabular}

relative to the data and was subtracted out by a linear extrapolation of the observed baseline drift prior to the shock arrival.

\section{Discussion}

Sound velocities of anorthosite from this study can be compared to those measured ultrasonically for anorthosite rocks of similar composition [Birch, 1960, 1961; Simmons, 1964; Anderson and Liebermann, 1968; Liebermann and Ringwood, 1976]. At $\mathrm{T}=25^{\circ} \mathrm{C}$ and $\mathrm{P}>0.4$ to $1 \mathrm{GPa}$, longitudinal velocities have been measured in anorthosite with composition between $A_{n_{49}}$ and $A_{n_{56}}$ in the range $6.76 \leq \mathrm{v}_{\mathrm{p}} \leq 7.47 \mathrm{~km} / \mathrm{s}$ and shear velocities in the range $3.87 \leq v_{s} \leq 4.09 \mathrm{~km} / \mathrm{s}$. Bulk sound velocities

$$
\mathrm{v}_{\phi}^{2}=\mathrm{v}_{\mathrm{p}}^{2}-\frac{4}{3} \mathrm{v}_{\mathrm{s}}^{2}
$$

are therefore in the range $5.04 \leq \mathrm{v}_{\phi} \leq 5.99 \mathrm{~km} / \mathrm{s}$.

We have adapted values of $6.85,3.60$, and $5.44 \pm 0.07$ $\mathrm{km} / \mathrm{s}$ for values of $v_{p o}, v_{s o}$, and $v_{\phi o}$, respectively, the zero pressure sound speeds of $\mathrm{An}_{40}$ using the collected data of

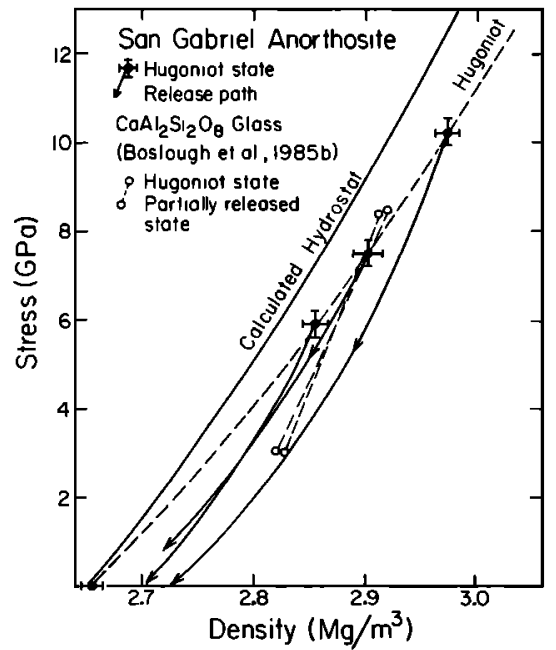

Figure 5. Hugoniot states and release paths of San Gabriel anorthosite. Included are two Hugoniot states of anorthite glass [Boslough et al., 1985b], with respective partial release states. Hydrostat assumes $\mathrm{K}_{\mathrm{os}}=79 \mathrm{GPa}$.
Liebermann and Ringwood [1976]. In order to compare our results to those expected for the longitudinal wave speeds at high pressure, we have used the Eulerian finite strain formulation of Sammis et al. [1970] (see also Burdick and Anderson [1975]) to predict values of $\mathrm{v}_{\mathrm{p}}$ along an isentrope:

$$
\begin{aligned}
\mathrm{v}_{\mathrm{p}}(\mathrm{P})^{2} & =\mathrm{v}_{\mathrm{po}}^{2}(1-2 \epsilon)\left[1-2 \epsilon\left(3 \mathrm{~K}_{\mathrm{os}} \mathrm{D}_{\mathrm{p}}-1\right)\right] \\
\mathrm{P} & =-3 \mathrm{~K}_{\mathrm{os}}(1-2 \epsilon)^{5 / 2}(1+2 \epsilon \xi) \epsilon
\end{aligned}
$$

where $\mathrm{K}_{\mathrm{os}}=79 \mathrm{GPa}$ is the zero pressure isentropic bulk modulus. Here the Eulerian volumetric strain is

$$
\epsilon=\left[1-\left(\rho / \rho_{0}\right)^{2 / 3}\right] / 2
$$

the finite strain parameter $\xi$ is

$$
\xi=\frac{3}{4}\left[4-\left(\mathrm{dK}_{\mathrm{s}} / \mathrm{dP}\right)_{s}\right]
$$

and

$$
\mathrm{D}_{\mathrm{p}}=\mathrm{d} \ln \mathrm{v}_{\mathrm{p}} / \mathrm{dP}
$$

No well-constrained values of $\xi$ and $D_{p}$ for any feldspar have yet been measured. Using data for other minerals

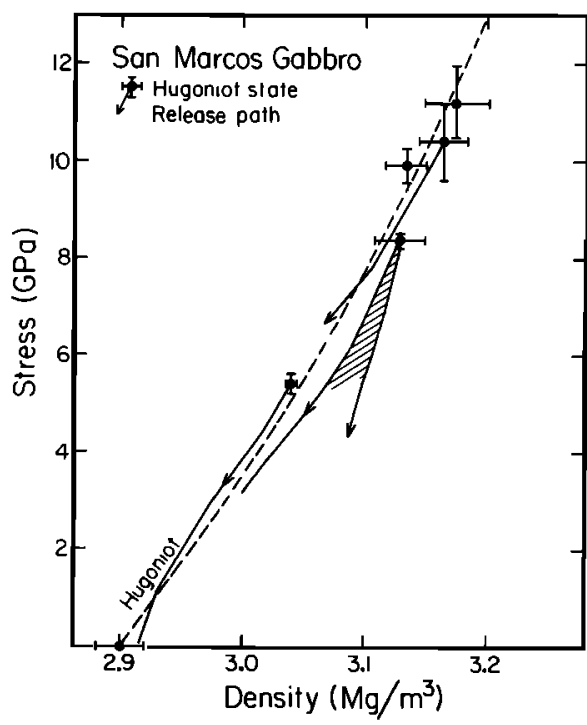

Figure 6. Hugoniot states and partial release paths of San Marcos gabbro. Noisy particle velocity records precluded determination of release to zero stress. Two interpretations are given for the release data for shot 573 . 


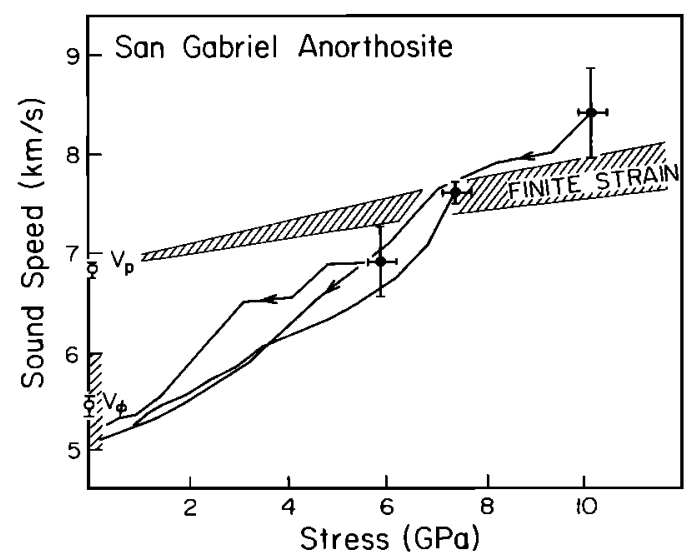

Figure 7. Eulerian sound speeds along release paths of shocked San Gabriel anorthosite. Hatched region indicates range of possible zero pressure bulk sound velocities.

[Anderson et al., 1968] as a guide, we have adopted values in the range

$$
-1.5 \leq \xi \leq-0.75
$$

and

$$
0.012 \leq \mathrm{D}_{\mathrm{p}} \leq 0.019 \mathrm{GPa}^{-1}
$$

to estimate the variation of $v_{p}$ with pressure (Figure 7). Figures 5 and 7 demonstrate that in all three shock wave experiments carried out on anorthosite, the initial sound velocity immediately behind the shock front was close to the expected longitudinal velocity, indicating that the material has retained strength. In all cases the sound speed decreased markedly upon unloading and approached the bulk sound speed $v_{\phi}$ as the rock was released to zero pressure. This implies a subsequent loss of shear strength, indicating elasto-plastic or elasto-hydrodynamic unloading behavior [e.g., Lee, 1971].

Using equation (8) and $\mathrm{K}_{\mathrm{og}}=79 \mathrm{GPa}$, we constructed a hydrostat (isentrope) in the stress-density plane (Figure 5). An ideal elasto-plastic solid, retaining strength in the shock state, would be expected to achieve Hugoniot states having a greater shock stress, at a given density, than those of the hydrostat by the amount $4 / 3 \tau$, where $\tau$ is the shear strength of the material [Davison and Graham, 1979], above the Hugoniot elastic limit. The hydrostat defines the lower limit of the Hugoniot for material which demonstrates elastic-hydrodynamic behavior, losing strength on compression.

There are two possible interpretations of the observation that the Hugoniot lies well below the calculated hydrostat. First, it is possible that the assumed bulk modulus (79 GPa) is too large. A lower effective bulk modulus, $\sim 65 \mathrm{GPa}$, would be required to bring the hydrostat into coincidence with the observed Hugoniot. Moreover, if the anorthosite is considered an elasto-plastic solid, with nonzero strength, the required bulk modulus would need to be significantly less than $65 \mathrm{GPa}$. A much reduced bulk modulus $(<65 \mathrm{GPa})$ is discordant with the extensive ultrasonic measurements which have been carried out on this type of plagioclase [Liebermann and Ringwood, 1976]. For this reason, we prefer a second hypothesis involving one or more phase transitions occurring below, or within, the range of our present data.

$A$ phase transformation such as

$$
\begin{gathered}
\mathrm{NaAlSi}_{3} \mathrm{O}_{8} \text { (albite) } \rightarrow \mathrm{NaAlSi}_{2} \mathrm{O}_{6} \text { (jadeite) } \\
+\mathrm{SiO}_{2} \text { (quartz or coesite) }
\end{gathered}
$$

could begin to occur at the stress levels of the present experiments, especially if it took place within a minor population of shear band heated zones [Grady, 1980]. We suggest the occurrence of reaction (14) in light of the identification of shock-induced formation of jadeite from shocked oligoclase in material from the Ries Crater in Germany [James, 1969]. The assemblage (anorthite) $38+$ (jadeite + quartz) 62 has a density of $3.01 \mathrm{Mg} / \mathrm{m}^{3}$, and

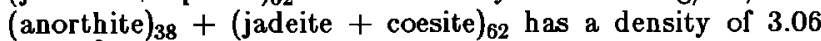
$\mathrm{Mg} / \mathrm{m}^{3}$. At $293^{\circ} \mathrm{K}, \mathrm{NaAlSi}_{2} \mathrm{O}_{6}+\mathrm{SiO}_{2}$ are the stable phases above 0.6 GPa [Clark, 1966]. The present experiments are well above the transformation pressure, so the only barriers to the phase transition are kinetic. The zero pressure density of the released anorthosite can be used to estimate the maximum amount of material transformed. For example, the final densities are in the range 2.69-2.73 $\mathrm{Mg} / \mathrm{m}^{3}$, which requires a maximum transformation of from 5-19 \% of the albite to high-pressure phases if the release path is along the hydrostat of the high-pressure phases. The possibility of pore space crushing and irreversible compaction would bring this estimate down somewhat. The data clearly show that the fraction of albite transformed to high-pressure phases is an increasing function of peak stress. This result is analogous to the conclusion of Grady et al. [1974] for higher pressures that the release path of shocked polycrystalline quartz is controlled by the quartz $\rightarrow$ stishovite transition. A clear case cannot be made for the retention or loss of shear strength or existence of phase transitions in gabbro due to the lower quality of the data. However, in most of the experiments the measured sound velocities are consistently lower for the gabbro than for the anorthosite. The release data are not of good enough quality to resolve whether the release paths are above the Hugoniot.

\section{Conclusions}

Since the unloading wave speed approaches the bulk sound speed, we conclude that San Gabriel anorthosite loses shear strength upon release from shock compression to pressures greater than $6 \mathrm{GPa}$. This material's release behavior can be partially attributed to the phase transformation of albite to jadeite and quartz or coesite. The amount of material transformed is likely to be controlled by kinetics and appears approximately to be an increasing function of shock pressure. This may be due to the localization of shock heating into shear bands, in which the temperature is high enough for the phase transition to occur. The mechanical result of the shear banding is hypothesized to be fluidlike rheological behavior upon release [Grady et al., 1975; Grady, 1980]. The hydrodynamic behavior of shocked anorthosite will result in less rapid attenuation of a decaying shock wave than obtained in the usual elasticplastic rheological model.

In calculations by O'Keefe and Ahrens [1977] of energy partitioning of a hypervelocity impact on to the anorthosite surface of a planet, the release behavior of the rock was assumed to be elastic-plastic [Fowles, 1960; Davison and Graham, 1979]. This assumption would tend to overestimate the attenuation of the shock wave due to catch-up of rarefaction waves. Thus a larger quantity of surface material is shocked above a given pressure, and estimates by O'Keefe and Ahrens [1977] of the fraction of meteoroid kinetic energy deposited in the planetary surface material will be too low.

Acknowledgments. We appreciate the assistance of $\mathrm{E}$. Gelle, W. Ginn, J. Long, and M. Long in building and carrying out experiments. We thank $R$. Heuser, $R$. Hill, and $\mathrm{S}$. Rigden for analyzing rock samples and S. Sondergaard for help in fabricating gauges. We are grateful to $O$. Ander- 
son and D. Grady for their helpful comments. This work was supported under NASA grant NGL 05-002-105. Contribution 4013, Division of Geological and Planetary Sciences, Pasadena, California 91125.

\section{References}

Ahrens, T. J., C. F. Petersen, and J. T. Rosenberg. Shock compression of feldspars, J. Geophys. Res., 74, 27272746, 1969 .

Ahrens, T. J., J. H. Lower, and P. L. Lagus, Equation of state of forsterite, J. Geophys. Res., 76, 518-528, 1971.

Anderson, O. L., and R. C. Liebermann, Sound velocities in rocks and minerals; experimental methods, extrapolations to very high pressures, results, in Physical Acoustics IVB, edited by W. P. Mason, pp. 330-472, Academic, Orlando, Fla., 1968.

Anderson, O. L., E. Schreiber, R. C. Liebermann, and N. Soga, Some elastic constant data on minerals relevant to geophysics, Rev. Geophys., 6, 491-524, 1968.

Birch, F., The velocity of compressional waves in rocks to 10 kilobars, 1, J. Geophys. Res., 65, 1083-1102, 1960.

Birch, F., The velocity of compressional waves in rocks to 10 kilobars, 2, J. Geophys. Res., 66, 2199-2224, 1961.

Boslough, M. B., Shock wave properties and high-pressure equations of state of geophysically important materials, Ph.D. thesis, Calif. Inst. of Technol., Pasadena, 1983.

Boslough, M. B., T. J. Ahrens, and A. C. Mitchell, Shock temperatures in anorthite glass, Geophys. J. R. Astron. Soc., in press, 1985a.

Boslough, M. B., S. M. Rigden, and T. J. Ahrens, Hugoniot equation of state of anorthite glass and lunar anorthosite, Geophys. J. R. Astron. Soc., in press, $1985 \mathrm{~b}$.

Burdick, L. and D. L. Anderson, Interpretation of velocity profiles of the mantle, J. Geophys. Res., $\underline{80}$, 1070-1074, 1975.

Carter, B. A., Field petrology and structural development of the San Gabriel anorthosite-syonite body, Los Angeles County, California, in Geologic Excursion in the Transverse Ranges, edited by J. D. Cooper, pp. 1-47, Geological Society of America, Boulder, Colo., 1982.

Clark, S. P., Jr., High-pressure phase equilibria, in Handbook of Physical Constants, edited by S. P. Clark, Jr., pp. 345-883, Geological Society of America, Boulder, Colo., 1966.

Cowperthwaite, M., and R. F. Williams, Determination of constitutive relationships with multiple gages in nondivergent flow, J.Appl. Phys. 42, 456-462, 1971.

Davison, L., and R. A. Graham, Shock compression of solids, Phys. Rep., 55, 255-379, 1979.

Dremin, A. N., and K. K. Shvedov, The determination of Chapman-Jouguet pressure and of the duration of reaction in the detonation wave of high explosives, Zh. Prikl. Mekh. Tekh. Fiz., 2, 154-159, 1964.

Fowles, G. R., Attenuation of the shock wave produced in a solid by a flying plate, J.Appl.Phys., 31, 655-661, 1960.

Fowles, R., and R. F. Williams, Plane stress wave propagation in solids, J. Appl. Phys, 41, 360-363, 1970.

Grady, D. E., Shock deformation of brittle solids, J. Geophys. Res., 85, 913-914, 1980.

Grady, D. E., and W. J. Murri, Dynamic unloading in shock compressed feldspar, Geophys. Res. Lett., 3, 472474, 1976 .

Grady, D. E., W. J. Murri, and G. R. Fowles, Quartz to stishovite: Wave propagation in the mixed phase region, J. Geophys. Res. 79, 332-338, 1974.

Grady, D. E., W. J. Murri, and P. DeCarli, Hugoniot sound velocities and phase transformations in two silicates, J. Geophys. Res., 80, 4857-4861, 1975.

James, O. B., Jadeite: Shock-induced formation from oligoclase, Ries Crater, Germany, Science, 165, 1005-1008, 1969.

Jeanloz, R., and T. J. Ahrens, Anorthite: Thermal equation of state to high pressures, Geophys. J. R. Astron. Soc., 62, 529-549, 1980.

Kondo, K., Y. Yasumoto, H. Sugiura, and A. Sawaoka, Multiple reverberations in a layer structure observed by particle-velocity and pressure gauges, paper presented at the 31st Aeroballistic Range Association Conference, Pasadena, California, 1980.

Lange, M., T. J. Ahrens, and M. B. Boslough, Impact cratering and spall fracture of gabbro, Icarus, $\underline{58}$, 383$395,1984$.

Larson, D. B., and G. D. Anderson, Plane shock wave studies of porous geologic media, J.Geophys. Res., $\underline{\text { 84, }}$ 4592-4600, 1979.

Lee, E. H., Plastic-wave propagation analysis and elasticplastic theory at finite deformation, in Shock Waves and the Mechanical Behavior of Solids, edited by J. J. Burke and V. Weiss, pp. 3-19, Syracuse University Press, Syracuse, N. Y., 1971.

Liebermann, R. C., and A. E. Ringwood, Elastic properties of anorthite and the nature of the lunar crust, Earth Planet. Sci. Lett., 31, 69-74, 1976.

Marsh, S. P., LASI, Shock Hugoniot Date, 680 pp. University of California Press, Berkeley, 1980.

McQueen, R. G., S. P. Marsh, and J. N. Fritz, Hugoniot equation of state of twelve rocks, J. Geophys. Res., 72, 4999-5936, 1967.

McQueen, R. G., S. P. Marsh, J. W. Taylor, J. N. Fritz, and $W$. J. Carter, The equation of state of solids from shock-wave studies, in High Velocity Impact Phenomena, edited by R. Kinslow, pp. 294-419, Academic, Orlando, Fla., 1970.

Miller, F. S., Petrology of the San Marcos gabbro, Southern California, Geol. Soc. Am. Bull., 48, 1397-1426, 1937.

O'Keefe, J. D., and T. J. Ahrens, Impact-induced energy partitioning, melting, and vaporization on terrestrial planets, Proc. Lunar Sci. Conf., 8th, 3357-3374, 1977.

Peterson, C. F., W. J. Murri, and M. Cowperthwaite, Hugoniot and release-adiabat measurements for selected geologic materials, J. Geophys. Res. 75, 2063-2072, 1970.

Sammis, C., D. Anderson, and J. Jordan, Application of isotropic finite strain theory to ultrasonic and seismological data, J. Geophys. Res., 75, 4478-4480, 1970.

Seaman, L., Lagrangian analysis for multiple stress or velocity gauges in attenuating waves, J.Appl. Phys. 45, 4303-4314, 1974.

Simmons, G., Velocity of shear waves in rocks to 10 kilobars, 1, J. Geophys. Res., 69, 1123-1130, 1964.

Watt, J. P., and T. J. Ahrens, Shock compression of single-crystal forsterite, J.Geophys. Res, , 88, 9500-9512, 1983.

T. J. Ahrens, Seismological Laboratory, California Institute of Technology, MS/252-21, 1201 E. California Blvd. Pasadena, CA 91125.

M. B. Boslough, Sandia Laboratories, Division 1131, Albuquerque, NM 87185.

(Received February 29, 1984; revised February 12, 1985; accepted March 11, 1985.) 